\title{
Las procesiones por la gran sequía de Valencia a través de las crides del Municipio (1455-1457). La ciudad como escenario de piedad
}

\author{
"Tot perdut e acabat". \\ The processions for the Great Drought of Valencia through the crides of \\ the Municipality (1455-1457). The city as stage of piety
}

Francisco ORTS RUIZ

Universidad Nacional de Educación a Distancia

ORCID: http://orcid.org/0000-0002-2328-6553 / forts@geo.uned.es

DOI: http://dx.doi.org/10.18002/da.v0i18.5900

Recibido: 15-IV-2019

Aceptado: 8-VIII-2019

RESUMEN: La ciudad y el Reino de Valencia vivieron entre los años 1455 y 1557 una de sus mayores sequías, tal y como se transmite de la documentación oficial y de los escritos de los cronistas de la época. Uno de los recursos más utilizados para combatir estas calamidades fue la convocatoria de procesiones en las que la población rogaba por el fin de estas. Proponemos en este artículo una introducción al estudio de estas manifestaciones de piedad desde el análisis de sus itinerarios, en un intento de reconstruir parte del entramado de la piedad urbana en la ciudad medieval y su paisaje sonoro y visual.

Palabras clave: Valencia; Sequía; Procesiones; Piedad popular; Urbanismo; Celebraciones urbanas; Paisaje sonoro.

ABSTRACT: The City and the Kingdom of Valencia experienced, between the years 1455 and 1557, one of its greatest droughts, as it is transmitted by the official documentation and the writings of the chroniclers of that time. One of the most usual resources to fight against these calamities was the call for processions in which the population begged for their end. In this paper we propose an introduction to the study of these manifestations of piety from the analysis of their itineraries, in an attempt to rebuild a part of the scene of urban piety in the medieval city and the sonic and visual landscapes of these processions.

Keywords: Valencia; Drought; Processions; Popular piety; Urbanism; Urban celebrations; Soundscape.

"Que per sa misericòrdia e clemència infinida nos vulla donar pluja sobre la terra". Con estas palabras se dirigía el Consell, máxima autoridad municipal en la Valencia foral, a los habitantes de la ciudad, por medio de una crida o pregón en el que se les convocaba a acudir a una procesión por la sequía que comenzaba a sufrir la capital ${ }^{1}$. Entre el 31 de octubre de 1455 y el 15 de abril de 1458 los vecinos escucharon las mismas palabras en 37 ocasiones, pues este fue el número de

${ }^{1}$ Archivo Histórico Municipal de Valencia (AHMV), Manuals de Consells, A36, f. 52v. Valencia, 3 de enero de 1456. 
procesiones convocadas entre las dos fechas para pedir el fin de la sequía.

Esta fue una de las peores carestías de agua que sufrió la Valencia medieval. Así queda patente si consultamos el dietario de la época escrito por Melcior Miralles, conocido como la Crònica del Capellá d'Alfons el Magnànim (ca. 1470), que define este periodo de escasez de agua como la gran secada, cuyas lamentables consecuencias enumera en el siguiente fragmento, del cual, por su poder evocador, hemos extraído el título del presente artículo: "En l'any de 1455, e 56, e 57, fonch tan gran secada en regne de València que molts rius se són sequats, la major part de les fonts seques, molts lochs no tenen aygua per poder beure, l'Albufera de València totalment venir a sequar, que no y romàs un pex; los esplets e fruyts de les terres són perduts per la gran sequada; mercaderies, hoficis, tot perdut e acabat"2.

Aunque es sabida la tendencia a la exageración de los cronistas y que sus opiniones deben ser tratadas con cautela, el texto de Miralles va acompañado por el ya comentado hecho de que se convocara un número extremadamente elevado de procesiones en la ciudad en este periodo, lo que nos habla de la excepcionalidad y crudeza de esta sequía ${ }^{3}$.

El objetivo de este artículo es mostrar cómo durante este periodo la ciudad de Valencia, sus calles y sus plazas, se convirtieron en un auténtico escenario de devoción. Estudiar los itinerarios de las procesiones nos ayudará a realizar un mapa de los recorridos seguidos por estas celebraciones, así como a señalar los lugares elegidos por los

\footnotetext{
${ }^{2}$ Melcior Miralles, Crònica i dietari del Capellá d'Alfons el Magnànim, ed. por Mateu Rodrigo Lizondo (València: Universitat de València, 2011), 236-237. (“En el año de 1455, y 56, y 57 hubo tan gran sequía en el Reino de Valencia que muchos ríos se secaron, la mayor parte de las fuentes secas, muchos lugares no tenían agua para poder beber, la Albufera de Valencia se secó totalmente, que no quedó ni un pez; las cosechas y frutos de las tierras fueron perdidos por la gran sequía; mercaderías, oficios, todo perdido y acabado". Todas las traducciones del autor).

${ }^{3}$ Por ejemplo, 1456 es el año con más procesiones de todo el siglo $\mathrm{XV}$, con un total de 22 .
}

valencianos para desarrollar sus rituales de culto, destacando el papel de las procesiones como elemento vertebrador de la sociedad medieval.

Pero antes de dedicarnos a las procesiones valencianas, será interesante detenernos un instante en el porqué de estas celebraciones. Las manifestaciones públicas por rogativas y letanías tienen sus orígenes en la alta Edad Media. Concretamente se toma como iniciador de las letanías al obispo san Mamerto de Vienne (ca. 400-475), quien, para luchar contra una epidemia de peste en su ciudad convocó tres procesiones con ruegos y cantos devocionales tres días antes de la fiesta de la Ascensión, en la segunda mitad del siglo $\mathrm{V}^{4}$. Otro ejemplo fundacional, quizá más conocido, sería la procesión convocada por el papa san Gregorio Magno en Roma en 590, para luchar, asimismo, contra una epidemia de peste, y que finalizó con la milagrosa aparición de un ángel en el castillo hoy conocido como Sant'Angelo ${ }^{5}$.

Como vemos en estos dos ejemplos tempranos, el cristianismo, desde casi sus inicios, empleó las procesiones, los ruegos y las letanías como armas para luchar contra catástrofes y calamidades. El ejemplo de Vienne y Roma pronto se expandió por todo el orbe cristiano y ocupó toda la Edad Media, sobre todo a partir del siglo XIV .

Si nos centramos en la península ibérica y acudimos a fuentes más cercanas cronológicamente al periodo que nos ocupa, observamos que existe un paralelo entre el pecado y la calamidad. Es decir, se traduce el

\footnotetext{
${ }^{4}$ Armando Alberola Romá, "Procesiones, rogativas, conjuros y exorcismos: el campo valenciano ante la plaga de langosta de 1756", Revista de Historia Moderna. Anales de la Universidad de Alicante, no 21 (2003), 37-38.

${ }^{5}$ André Vauchez, "Liturgie et culture folklorique: les rogations dans La Legénde Dorée de Jacques Voragine", en Fiestas y liturgia, Actas del congreso celebrado en la Casa de Velázquez (Madrid: Casa de Velázquez, Universidad Complutense, 1988), 21.

${ }^{6}$ Rafael Narbona, La ciudad y la fiesta: cultura de la representación en la sociedad medieval (siglos XIII-XV) (Madrid: Síntesis, 2017), 145-148.
} 
origen de todo tipo de catástrofes en el mal comportamiento cristiano de la sociedad, por lo que, para intentar mitigarlas, será necesario purgar estas faltas. Ilustraremos este pensamiento con dos ejemplos medievales. El primero es un texto extraído de $E l$ Corbacho (1438), de Alfonso Martínez de Toledo (1398-ca. 1468): "E asy nuestro Señor, segund la su gran be[ni]gnidad, nos castiga por mortandades, malos tienpos, adversydades, sequedades de pocas aguas, guerras, enfermedades, pasyones, dolores de cada día e afanes; que ya los tienpos non vienen como solían, porque los onbres e criaturas non biven como byvían"7.

Vemos aquí cómo este "no vivir como vivían" de los hombres se convierte en el principal motivo de las calamidades que el creador envía a los habitantes de la tierra como castigo a su mal comportamiento. Unas décadas anterior a Martínez de Toledo, el influyente franciscano Francesc Eiximenis (1330-1409), a finales del siglo XIV, se expresaba con las siguientes amenazas punitivas en su Vida de Jesucrist (1403), redactada en la propia ciudad de Valencia: "Per la qual cosa lavors nostre Senyor trametrà generalment sobre la terra moltes plagues, ço és fams, grans cismes, divisions, mortandats, sovint terratrèmols, legostes e vèrmens contra los splets, diversitat de malalties, sequades, exorquies en arbres e en fonts e en altres coses..." ${ }^{\prime}$.

¿Cómo evitar todas estas calamidades? Para la sociedad medieval, la mejor manera de purgar los pecados será hacer pública

\footnotetext{
${ }^{7}$ Alfonso Martínez de Toledo, Arcipreste de Talavera o Corbacho, ed. por Joaquín González Muela (Madrid: Castalia Clásicos, 1970), 230.

${ }^{8}$ Albert Hauf i Valls, "Profetisme, cultura literària, i espiritualitat en la València del segle XV: d'Eiximenis i Sant Vicent Ferrer a Savonarola, passant pel Tirant lo Blanc", en Xàtiva, els Borja: una projecció europea, Catálogo de exposición (Xàtiva: Ajuntament de Xàtiva, 1995), 115. ("Por lo cual, luego nuestro Señor transmitirá generalmente sobre la tierra muchas plagas, esto es, hambres, grandes cismas, divisiones, mortandades, a menudo terremotos, langostas y gusanos contra las cosechas, diversidad de enfermedades, sequías, esterilidades en árboles y en fuentes y en otras cosas".
}

gala de la piedad colectiva. Encontraremos, pues, a lo largo de este periodo, y en el siglo $\mathrm{XV}$ en particular, toda una serie de actos de contrición que se traducirán en las mencionadas procesiones y misas, pero también en reparto de limosnas como acto de caridad y en ordenaciones contra prácticas poco honrosas, como la alcahuetería, el adulterio, la prostitución, el juego o incluso la longitud de las faldas de las mujeres. Así se hizo, por ejemplo, tras llegar la noticia a la ciudad de Valencia del terremoto que asoló Nápoles en 1456, en decisiones tomadas en reunión del Consell secret en enero de $1457^{9}$.

Es en este contexto donde debemos enmarcar las procesiones que tuvieron lugar en Valencia por la gran secada. Por ello nos disponemos a analizar los rasgos comunes de todas ellas. Para tal fin nos servirán como fuente las crides o pregones realizadas en la ciudad para convocar a la población, que se encuentran transcritas en la serie dedicada a los Manuals de Consells, los libros de actas del Municipio. Estas crides o pregones pueden ser descritas como una de las herramientas de comunicación más efectivas utilizadas por los poderes municipales durante la Edad Media, ya que, además de ser proclamadas de viva voz por el pregonero en las calles y plazas de la ciudad, eran también colgadas en las paredes y puertas de los principales edificios, produciéndose así una doble exposición de las órdenes, la oral y la escrita ${ }^{10}$.

${ }^{9}$ AHMV, Manuals de Consells, A36, ff. 156v-157v. Valencia, 15 de enero de 1457. Se tomaron decisiones contra "taffureries, blasfemies, males dones e alcavots, [...] e que alguna dona [...]no gos portar dins lo present Regne faldes de tres pals de largaria" ("tahurerías, blasfemias, malas mujeres y alcahuetes [...] y que alguna mujer [...] no ose llevar dentro del presente reino faldas de tres palos de largo". También contra la peste se tomaron este tipo de medidas "que fossen extirpats vicis e peccats de la ciutat axi com son jochs e los juradors blasfemadors alcavots anols fembres e altres" ("que fuesen extirpados vicios y pecados de la ciudad, así como son juegos y los juradores blasfemadores, alcahuetes, malas mujeres y otros"). Jacqueline Guiral, "L'evolution du paysage urbain à Valencia du XIII au XVI siècle", En la España medieval, nº 7 (1985), 1603.

${ }^{10}$ Manuel Peña Díaz, “Leer, oír y hablar: sonidos 
Al tratarse de ordenaciones promulgadas por las autoridades municipales, estas crides repiten siempre la misma estructura. Así, si nos detenemos a analizar el contenido de estos documentos, podremos encontrar que estos se encuentran estructurados siguiendo el siguiente esquema: fórmula inicial y ente convocante de la procesión; motivo de la procesión; información práctica, fecha (hora) e itinerario $y$, por último, mandatos a la población.

Para la realización de este artículo, si bien tendremos en cuenta todas las procesiones valencianas realizadas entre las fechas citadas, nos centraremos en una de las crides realizadas en este periodo de sequía, concretamente la publicada el 3 de enero de 1456, donde se convoca una procesión para el día siguiente con destino al convento del Carmen. El texto de esta crida nos servirá como modelo para analizar la organización y características de estas procesiones, ya que en todos estos escritos se repite, como ya se ha comentado, la misma estructura, con las únicas variantes relativas a la fecha, itinerarios y destino.

\section{"A LAOR E GLORIA". LA FÓRMULA DE INICIO, EL ENTE CONVOCANTE Y EL MOTIVO DE LA CELEBRACIÓN}

La fórmula inicial era siempre la misma, permitiendo así que el público pudiese identificar el tipo de mensaje desde el comienzo. Esto es importante, ya que el contenido de las crides podía ser tan variopinto como el anuncio de una entrada real, el aumento de impuestos, el pago de ayudas para el comercio del trigo o la prohibición de entrar vino en la ciudad. De ahí la importancia de que el encabezamiento de las crides estuviese codificado, de manera que los oyentes supiesen de qué tipo se trataba desde el comienzo. En el caso de las procesiones que nos ocupan,

cotidianos en la Barcelona del Quinientos", en Els sons de Barcelona a l'edat moderna, coord. por Tess Knighton (Barcelona: Museu d'Història de Barcelona Ajuntament de Barcelona-Institució Milà i Fontanals/CSIC, 2016), 113-129. el inicio será siempre el siguiente: "A laor e glòria de tota la Santa Trinitat e de la gloriosa Verge dona santa Maria mare de Jesus Christ e del benaventurat màrtir sent Vicent, ara oiats que us fan saber los honorables Justicia e Jurats de la ciutat de València"11.

Así, al escuchar este encabezamiento de voz del pregonero, los habitantes de Valencia sabían que se les estaba convocando a una procesión. Incluso consideramos altamente factible la hipótesis de que este tipo de crides tuvieran un toque de trompetas y atabales especial, para ser reconocidas rápidamente, aun antes de que el texto comenzase a ser declamado ${ }^{12}$. Este aspecto es también importante, ya que en Valencia el crida públich, cargo con el que se conocía al pregonero municipal, era también trompeta y encargado de coordinar al grupo de músicos del Consell, como se desprende de los documentos de pago $^{13}$. Si el mensaje a transmitir en la cri$d a$ era importante, esta se consideraba reial, lo que significaba que todos los trompetas y atabaleros municipales participaban en ella con sus toques. Por el contrario, si el pregón era considerado ordinario o general, tan solo el crida públich con su trompeta, o acompañado de un número reducido de sus compañeros, se encargaba de anunciar el contenido del texto a los habitantes de la ciudad y la

\footnotetext{
${ }^{11}$ AHMV, Manuals de Consells, A36, f. 52v. ("A loor y gloria de toda la Santa Trinidad y de la gloriosa Virgen doña santa María madre de Jesucristo y del bienaventurado mártir san Vicente, oíd ahora que os hacen saber...".

12 Este tema se desarrolla con más amplitud en
} nuestra tesis doctoral en curso.

${ }^{13}$ En relación a los pagos a los músicos municipales, en los libros de cuentas del Consell (claveria) siempre aparece como cobrador el crida públich, que deberá repartir los salarios entre el resto. Sirva como ejemplo un recibo de cobro: "De nos pagats an Ramon Artús, per sí e sos companyons XIII sous VI diners a aquells deguts per rahó d'una crida". AHMV, Claveria Comuna, J29, f. 12r. Valencia, 12 de agosto de 1401. El análisis de estos libros es muy interesante en cuanto a la organización de las procesiones, ya que se registran los pagos a los participantes asalariados, sobre todo los músicos y actores (en el caso del Corpus Christi). 
fórmula inicial se reducía al ara oiats que us fan saber ("oíd ahora que os hacen saber") ${ }^{14}$.

En cuanto a los convocantes, tal y como aparece en el texto, tras la exhortación del pregonero a los ciudadanos para que prestaran atención (ara oiats), estos son el Justicia y los Jurats de la ciudad. El Justicia era, desde tiempos de Jaume I, el encargado de los asuntos judiciales. Ya en época de Jaume II, en 1321, el aumento de la demanda de este cargo hizo que se dividiera en dos, el Justicia criminal y el Justicia civil. Aunque la crida que nos ocupa no especifica cuál de los dos justícies ordenaba su publicación, era el Justicia criminal el que poseía dicha prerrogativa, así como la de asumir de manera honoraria el papel de presidente del gobierno municipal, encabezar la milicia ciudadana y enarbolar el estandarte de la ciudad en caso de celebración o amenaza ${ }^{15}$. En cuanto a los Jurats, consistían en seis próceres (cuatro ciudadanos y dos caballeros) que conformaban el órgano ejecutivo del Consell de la Ciutat, a modo de diputación permanente, ya que el mencionado organismo solo se reunía en ocasiones excepcionales o marcadas por el calendario (normalmente por elecciones de cargos) ${ }^{16}$.

Como vemos por la afiliación de estos cargos, las procesiones siempre son organizadas y convocadas por el poder político municipal. Son los miembros del Consell los que hacen el llamamiento a la población y los que corren con los gastos, aunque esto siempre se realiza, como el texto de la crida

${ }^{14}$ Sirva como ejemplo de crida general la publicada el 15 de junio de 1480 por Pere Artús, en la que se especifica que dicho trompeta públich la realizó "ell sols" y cuyo inicio recoge la fórmula "ara oiats que us fan saber". AHMV, Manuals de Consells, A42, ff. 15r-15v.

${ }^{15}$ Rafael Narbona Vizcaíno, "La justicia municipal en el Reino de Valencia (ss. XIII-XV)", Anales de la Universidad de Alicante. Historia Medieval, no 18 (2012-2014), 347-357; Amadeo Serra Desfilis, "Memoria de reyes y memorias de la ciudad: Valencia entre la conquista cristiana y el reinado de Fernando el Católico (1238-1476)", Codex Aquilarensis, no 34 (2018), 165-166.

${ }^{16}$ Rafael Narbona Vizcaíno, Valencia, municipio medieval: poder político y luchas ciudadanas (1239-1418) (Valencia: Ayuntamiento de Valencia, 1995). muestra más adelante, "ab concòrdia ab lo capitol de la Seu", es decir, de acuerdo con el cabildo catedralicio. Por este motivo el punto de salida será siempre el mismo, la catedral. La única variación será la utilización de una de sus tres puertas ${ }^{17}$.

El siguiente punto del pregón, siguiendo la estructura que hemos trazado, se centra en informar a los vecinos del motivo de ese hecho extraordinario: "Que per recaptar gràcia e misericòrdia de nostre senyor Déu, que per sa clemència infinida nos vulla donar pluja sobre la terra mitjançant la qual los splets que acomanats li son puxen fructificar e aconseguir la fi que deben haver"18.

Como vemos, la causa de la procesión queda clara en la crida, donde se hace referencia muy explícita a las cosechas (splets). El objetivo, por tanto, es rogar a Dios por el fin de la sequía y la llegada de las lluvias, que ayuden a fructificar unas cosechas que ya le han sido encomendadas.

"FARÀN DEVOTA E SOLENNE PROCESSÓ". INFORMACIONES PRÁCTICAS E ITINERARIO

Pasemos ahora a analizar los itinerarios y destinos de las procesiones, que, como hemos visto, aparecían especificados en los textos de los pregones (Tabla 1). Si nos fijamos, las dos primeras salidas, en noviembre de 1455 , fueron hacia el convento

${ }^{17}$ La convocatoria de las procesiones por los poderes políticos nos acerca al concepto de religion civique acuñado por Vauchez, donde se subraya la importancia de la relación entre lo cívico y lo religioso en la Edad media. André Vauchez, ed., La religion civique à l'époque médiévale et moderne (Chretienté et Islam) (Rome: École Française de Rome, 1995), 1-5. Sobre las procesiones como fenómeno socio-religioso consultar Fernando Galtier, "Los orígenes de la paraliturgia procesional de semana santa en Occidente", Aragón en la Edad Media, nº 20 (2008), 349-360, especialmente 351.

${ }^{18}$ AHMV, Manual de Consells, A36, f. 52v. ("Que por recabar gracia y misericordia de nuestro señor Dios, que por su clemencia infinita nos quiera dar lluvia sobre la tierra mediante la cual las cosechas que encomendadas le son puedan fructificar y conseguir el fin que deben tener". 


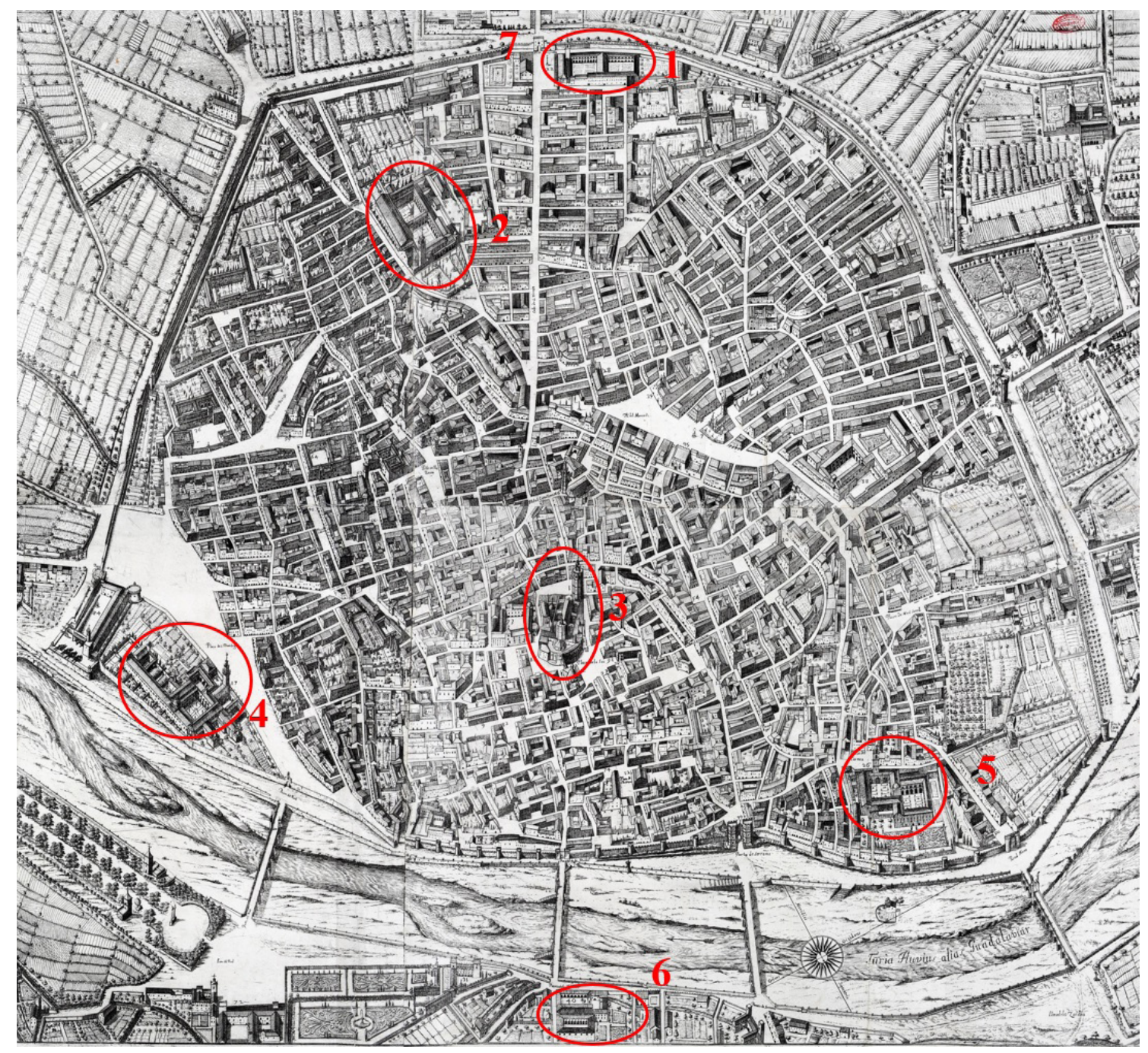

- Fig. 1. Tomás Vicente Tosca. Plano de Valencia. 1738. Detalle. 1. Convento de san Agustín; 2. Convento de san Francisco; 3. Catedral; 4. Convento de santo Domingo; 5. Convento del Carmen; 6. Monasterio de la Trinidad; 7. Puerta de san Vicente, salida hacia el convento homónimo. Ajuntament de València. Licencia: Wikimedia Commons CC BY SA. 04).

de San Agustín, concretamente a la capilla de Nuestra Señora de Gracia. Además, este fue el destino que tuvieron muchas de ellas (siete en total), entre ellas las últimas, que se hicieron en acción de gracias por la llegada de la lluvia. La explicación de la importancia de esta capilla reside en la imagen custodiada en ella, la cual, desde mediados del siglo XIV, había adquirido fama de milagrosa en la ciudad ${ }^{19}$. Se trataba de un icono bizantino,

\footnotetext{
${ }^{19}$ Para profundizar en la historia de dicho convento y en la de la imagen de nuestra señora de Gracia, consultar Daniel Benito Goerlich, El Real Monasterio de San Agustín de Valencia: parroquia de Santa Catalina Mártir y
}

al que ya su aparición extraordinaria dotó de cierto poder taumatúrgico para los habitantes de Valencia. Según la tradición, dos frailes salieron del convento con el objetivo de encargar una pintura de la Virgen para decorar su iglesia. Al poco se encontraron con un peregrino que les preguntó a dónde se dirigían. Tras conocer el objeto de su salida, el peregrino obsequió a los frailes con el icono de la virgen. Al marchar hacia el convento, los frailes se percataron que el dicho peregrino era, en realidad, un ángel. Esta leyenda

San Agustín Obispo (Valencia: Institució Alfons el Magnànim, 2015). 
arraigó en la ciudad y la imagen adquirió gran fama, contándose por decenas las procesiones que se realizaron hacia su capilla ${ }^{20}$.

Si nos fijamos en el resto de los destinos de las procesiones (Tabla 1), vemos cómo, durante el periodo que nos ocupa, estas se dirigieron a los principales conventos de la ciudad: San Agustín, Santo Domingo (o Predicadores), el Carmen, la Trinidad, San Francisco y San Vicente Mártir. El análisis de las fuentes indica claramente cómo muchos de los centros se repiten. Si los situásemos en el mapa, obtendríamos una cartografía de los principales lugares dedicados a la devoción popular en la Valencia de mediados del siglo $\mathrm{XV}^{21}$ (Fig. 1).

La pregunta que surge en este momento es por qué se eligieron estos centros y no otros. El caso más destacado y repetido, el del icono de Nuestra Señora de Gracia, ya ha sido comentado, por lo que consideramos también necesario detenernos brevemente en el significado de algunos de estos lugares sagrados para la ciudad de Valencia. Comenzaremos por el convento de santo Domingo, también conocido como de Predicadores. Fundado por Jaume I tras la conquista de la ciudad en 1239, pronto adquirió gran presencia urbana. En él vivió san Vicente Ferrer (1350-1419), quien además fue su prior. La celda de este santo, tras su canonización en 1455, fue convertida en lugar de culto y veneración. Además, este convento tuvo una gran importancia política, ya que en su interior se celebraron diversas sesiones de las cortes del Reino de Valencia. Las proce-

${ }^{20}$ Daniel Benito Goerlich, El icono de Nuestra Señora de Gracia de Valencia: historia de la imagen y su templo de San Agustín y Santa Catalina 700 años después de su fundación (Valencia: Ajuntament de València, 2007).

${ }^{21}$ La fundación de conventos de las órdenes mendicantes fue decisiva en el proceso de cristianización de la ciudad iniciado por Jaume I al finalizar la conquista, de ahí que adquirieran una gran importancia en el desarrollo de la Valencia medieval. Amadeo Serra Desfilis, "Gli ordini mendicanti e la città: localizzazioni conventuali e urbanizzazione a Valencia (seccoli XIII-XV", en Storie di città e architetture. Scritti in onore di Enrico Guidoi, a cura di Guglielmo Villa (Roma: Kappa, 2014), 96. siones que se dirigían a este cenobio tenían como objetivo venerar la imagen de Nuestra Señora de la Misericordia, que se hallaba en una de las capillas del claustro ${ }^{22}$.

Otro lugar destacado es el convento de san Vicente, conocido popularmente como la Roqueta. Situado fuera de las murallas de la ciudad, su origen está en el siglo IV, cuando se construyó un martyrium en el lugar donde se creía que había sido enterrado el diácono y mártir Vicente ${ }^{23}$. Tras la conquista cristiana por Jaime I, éste quiso restaurar el templo, en un claro ejemplo de justificación de su campaña militar al recuperar de los musulmanes un territorio anteriormente cristiano. Desde entonces el convento se convirtió en uno de los principales centros religiosos de la ciudad, debido a su marcada simbología y a estar dedicado al santo patrono de la misma. Por todo lo expuesto, es comprensible que el pueblo se encomendara a él para solucionar el mal estado de la ciudad debido a la crisis producida por la falta de agua ${ }^{24}$.

Por su parte, el convento de san Francisco fue también una fundación de época de la conquista cristiana, ya que Jaime I donó los terrenos a la orden franciscana para construir su cenobio en 1239. La fábrica de este convento también tuvo tintes legendarios, ya que, según la tradición, se situó en el mismo lugar donde se encontraba el palacio del rey Zeyt-Abu-Zeyt, donde fueron martirizados los frailes franciscanos Juan de Perugia y Pedro de Sassoferrato, que habían entrado en el territorio musulmán de Valencia en 1228 para predicar y evangelizar. Sea como fuere, este convento adquirió pronto fama y

${ }^{22}$ Emilio Callado Estela et al., El Palau de la Saviesa. El Reial Convent de Predicadors de València i la Biblioteca Universitària, Catálogo de la exposición (Valencia: Universitat de València, 2005).

${ }^{23}$ San Vicente Mártir fue uno de los más célebres mártires hispanos antiguos y su culto se extendió desde Valencia y Zaragoza hasta Portugal, Francia o Italia. Narbona, La ciudad y la fiesta..., 137-138.

${ }^{24}$ Rafaela Soriano Sánchez y Francisco José Soriano Gonzalvo, San Vicente Mártir y los lugares vicentinos en Valencia (Valencia: Ajuntament de València, 2001). 
se situó entre los más ricos y poderosos de la ciudad, especialmente entre los siglos XIV y XVI ${ }^{25}$.

El monasterio de la Trinidad fue una fundación regia, concretamente de la reina María de Castilla (1401-1458), esposa de Alfonso V (1396-1458), quien quedó en Valencia tras el traslado a Nápoles del Magnánimo. Aprovechando un cenobio preexistente, las obras del nuevo complejo dedicado a la orden de santa Clara comenzaron en 1445. Casi desde su fundación el centro se convirtió en un importante monasterio femenino y muchas de las hijas de las familias acaudaladas de Valencia habitaron sus celdas. La propia reina María fue sepultada en él tras su muerte en 1458 , de ahí que se uniera la piedad popular, visible en los casos anteriores, con la nobiliaria, siendo elegido este cenáculo por lo que suponía para la aristocracia de la ciudad ${ }^{26}$.

Por último, el convento del Carmen comenzó a construirse por privilegio de Pedro III de Aragón en 1281 como centro de la orden de los carmelitas descalzos en la ciudad. Al igual que otros cenobios, se construyó fuera de la muralla islámica y fue incluido en el interior del perímetro urbano por la nueva cerca construida en el siglo XIV. Situado en el barrio de Roteros, uno de los más activos de la ciudad medieval, pronto se convirtió en un lugar de gran devoción ${ }^{27}$.

Como hemos visto, todas estas edificaciones tenían su importancia, ya fuera por su fundación legendaria, por su relación con la conquista cristiana, por sus nexos con la monarquía o por el hecho de que albergaran alguna imagen de especial devoción. Si tenemos en cuenta que todas las procesiones que

${ }^{25}$ Salvador Aldana Fernández, coord., Monumentos desaparecidos de la Comunidad Valenciana (Valencia: Consell Valencià de Cultura, 1999).

${ }^{26}$ Daniel Benito Goerlich, El Real Monasterio de la Trinidad. Historia y Arte (Valencia: Consell Valencià de Cultura, 2008).

${ }^{27}$ Dolores García Hinarejos, Historia y arquitectura del convento del Carmen de Valencia (Valencia: Consorcio de Museos de la Comunidad Valenciana, 2009). se dirigían a estos edificios sagrados tenían su punto de salida y llegada en la catedral, podemos trazar los itinerarios de cada una de ellas. Para esta reconstrucción son muy útiles de nuevo los textos de las crides de cada una de estas celebraciones, ya que en muchas de estas relaciones hemos encontrado la descripción del itinerario exacto.

Sirva como ejemplo un extracto de la crida que estamos tomando como punto de partida en este artículo, dedicada a la procesión realizada al monasterio del Carmen el 4 de enero de 1456: “... Han ordenat ab concordia del honorable Capítol de la Seu de la dita ciutat que demà de matí faràn devota e solenne processó, la qual, partint de la dita Seu, eixirà per el portal de la plaça de les Corts e proseguint per la plaça de sant Bertomeu al carrer dels Serrans e per la Carniceria de Roteros hirá tot dret a nostra dona santa Maria del Carme, e aquí, donades dignes laors a nostre senyor Déu e a la dita Reina del Paradís, la dita processó eixirà del dit monestir e tornarà a la sglesia de sancta Creu e entrarà a dita sglesia, e donades aquí aximateix laors a nostre senyor Déu, eixirà per lo portal que va a la plaça del Alber e al carrer dels Teixidors e dret al carrer dels Cavallers e per les Corts tornarà en la dita Seu per lo dit portal dels Apòstols" 28 .

Si tenemos en cuenta los destinos de las procesiones al analizar el plano de la ciudad medieval, podremos comprobar cómo casi la totalidad de la trama urbana se convirtió en este periodo de sequía en un gran escenario en el que todos los estamentos mostraron su

${ }^{28}$ AHMV, Manuals de Consells, A36, ff. 52v-53r. Valencia, 3 de enero de 1456. ("... Han ordenado, de acuerdo con el honorable capítulo de la Seo de la dicha ciudad que mañana por la mañana harán solemne y devota procesión, la cual, partiendo de la dicha Seo, saldrá por el portal de la plaza de las Corts y prosiguiendo por la plaza de Sant Bertomeu a la calle del Serrans y por la Carnicería de Roteros irá todo recto a nuestra señora María del Carmen, y allí, dados dignos honores a nuestro señor Dios y a la dicha Reina del Paraíso, la dicha procesión saldrá de dicho monasterio y volverá a la iglesia de santa Creu y entrará en dicha iglesia, y dadas aquí así mismo alabanzas a nuestro señor Dios, saldrá por la puerta que va a la plaza del Alber y a la calle dels Teixidors y recto a la calle dels Cavallers y por les Corts volverá a la dicha Seo por el portal de los Apóstoles". 
piedad y devoción para conseguir la lluvia ${ }^{29}$. También se podrá constatar cómo ninguna de estas manifestaciones religiosas rebasó los límites de la ciudad cristiana, es decir, en ningún momento se adentró en lugares como la morería (todavía activa y ampliamente habitada a mediados del siglo XV) ${ }^{30}$. El caso de la judería es diferente, ya que esta quedó casi deshabitada y fue repoblada por cristianos tras el ataque que se produjo en 1391, aunque muchos judíos conversos continuaron viviendo en la ciudad, llegando a agruparse en cofradías como la de san Cristóbal ${ }^{31}$.

Tomando como referencia los itinerarios recogidos en las crides, sería altamente interesante poder realizar un trabajo de geolocalización urbana de estos recorridos procesionales, utilizando para ello las nuevas

\footnotetext{
${ }^{29}$ La situación estratégica de los conventos de las órdenes mendicantes cerca de las principales puertas de la ciudad favorecía este hecho. Así, desde finales del siglo XIII el convento de San Francisco dominaba la zona meridional de la trama urbana, el de Santo Domingo la oriental, el del Carmen el noroeste y el de San Agustín el sureste, estableciendo así un polígono imaginario que tendría como centro la catedral y la sede del poder político. Serra Desfilis, "Gli ordini mendicanti...", 102. Sobre la importancia de la estructura conventual de la ciudad y su evolución entre los siglos XIII y XVI consultar Miguel Falomir Faus, Arte en Valencia, 1472-1522 (Valencia: Consell Valencià de Cultura, 1996), 66-84.
}

${ }^{30}$ Manuel Ruzafa García, "Las actividades industriales de la morería de Valencia", en Actas del VI Simposio Internacional de Mudejarismo (Teruel: Centro de Estudios Mudéjares-Instituto de Estudios Turolenses,1993), 269-286.

${ }^{31}$ Sobre los judíos y conversos valencianos consultar José Hinojosa Montalvo, “En torno a los judíos valencianos. La recuperación de una memoria olvidada", Hispania: Revista Española de Historia, vol. 50, no 175 (1990), 921-940 y "Sederos conversos en la Valencia bajomedieval", Anales de la Universidad de Alicante. Historia Medieval, no 18 (2012-2014), 199 y 224; José María Cruselles, "Els conversos de València, el cens inquisitorial de 1506 i la família del mercader Lluís Vives", Futura, no 31 (2015), 16-17. Sobre los conflictos producidos por la participación de judíos y musulmanes en procesiones en la Corona de Aragón, consultar David Nirenberg, Communities of Violence. Persecution of Minorities in the Middle Ages (Princeton: Princeton University Press, 1996), 180-182. tecnologías y aplicaciones informáticas con el objetivo de poder señalar en el mapa de la ciudad dichos itinerarios, lo que nos permitiría visualizarlos sobre el plano y analizar qué calles y plazas eran las más utilizadas para estos actos, además de reconstruir su paisaje visual y sonoro, trabajo que esperamos poder desarrollar en un futuro ${ }^{32}$.

Es también enriquecedor rebasar el marco de las procesiones de devoción popular y analizar su recorrido en comparación con otro tipo de celebraciones, como por ejemplo las entradas reales y las procesiones del Corpus Christi ${ }^{33}$. Estas dos festividades pueden ser consideradas las más importantes en la ciudad medieval, siendo el Corpus una fiesta anual, mientras que las entradas tenían un carácter extraordinario, ya que tan sólo se realizaban cuando el rey visitaba la ciudad, especialmente en su primer recibimiento como monarca, cuando se producía la jura de los fueros ${ }^{34}$. En estos casos se produce un hecho relevante y es que las entradas reales, a partir de la realizada por Fernando I en 1414, van a seguir el itinerario de la procesión del Corpus ${ }^{35}$. Se estaba

\footnotetext{
${ }^{32}$ Para el desarrollo de esta idea se han tomado como referencia los trabajos realizados por los investigadores Juan Ruiz Jiménez e Ignacio José Lizarán Rus en su proyecto online "Paisajes sonoros históricos (c.1200-c.1800)", que tiene como objetivo principal cartografiar los sonidos urbanos de ciudades como Granada y Sevilla, no sólo relacionados con procesiones, sino en otro tipo de celebraciones urbanas, como entradas reales, desfiles, etc. Juan Ruiz Jiménez e Ignacio José Lizarán Rus, "Historical Soundscapes (c. 1200-c. 1800): An On-Line Digital Platform", en Tess Knighton y Ascensión Mazuela-Anguita, Hearing the city in Early Modern Europe (Turnhout: Brepols Publishers, 2018), 342-352. El proyecto online se puede consultar en el enlace web.

${ }^{33}$ Un análisis de la evolución del arte en Valencia relacionado con las entradas reales se encuentra en Falomir Faus, Arte en Valencia..., 397-417.

${ }^{34}$ Rafael Narbona Vizcaíno "Las fiestas reales en la ciudad de Valencia entre la Edad Media y la Edad Moderna (siglos XIV-XVII)", Pedralbes. Revista d'història moderna, $\mathrm{n}^{\mathrm{o}} 3$ (1993), 463-472.

35 En una decisión del Consell de 1418 prohibiendo rehacer las construcciones derribadas con motivo del arreglo de las calles, vemos cómo el recorrido del
} 
intentando así seguir el recorrido de la celebración anual más importante de la ciudad, creando un trazado fosilizado, una especie de vía sacra que era utilizada en los desfiles urbanos más importantes y que transcurría por espacios tan representativos como el portal dels Serrans y las calles dels Cavallers, sant Bertomeu o Bosseria y las plazas del Mercat, de la Figuera o de la Seu, y que se mantendría invariable hasta el siglo $\mathrm{XVIII}^{36}$. La gran diferencia entre este itinerario oficial fosilizado y los recorridos de las procesiones por rogativas está en que, en estas últimas, era el destino el que marcaba las calles y recorridos por los que transcurriría el cortejo. Es decir, dependiendo del convento o monasterio que se visitara el trazado variaría. Incluso podemos encontrar casos como el de la crida que analizamos en este artículo, en el que aparece más de un destino, o alguna parada secundaria, lo que obliga a modificar el recorrido. En este aspecto radica la novedad e interés de estas procesiones, ya que calles y plazas que no entraban en el itinerario festivo oficial entraban a formar parte de un recorrido devocional y quedaban integradas en un circuito que podía variar en cada ocasión que alguna calamidad lo requería, contribuyéndose también, con ello, a la mejora del trazado urbano de la ciudad por el embellecimiento que este tipo de celebraciones comportaba.

Si bien se ha comentado que lo habitual era ceñirse al perímetro de la ciudad, las procesiones de rogativas, en ocasiones, traspasaban el recinto amurallado de la

Corpus y de las entradas reales ya se reconoce como el mismo: "Que algú de qualsevol ley, estament o condició sia de huy avant no gos ni presumesca fer o refer en los carrers per on comunament pasa e es fa la processó de Corpore Christi e s'acostumen fer les entrades dels senyors Reys e Reynes en lo primer adveniment a la dita ciutat, per ningún temps algún barandat o exida novellament". AHMV, Manuals de Consells, A27. ff. 3v-4r, 17 de marzo de 1418.

${ }^{36}$ La tesis de Juliana Colomer ahonda en la estrecha relación entre fiesta urbana y urbanismo en Valencia. Desirée Juliana Colonmer, "Fiesta y urbanismo. Valencia en los siglos XVI y XVII" (tesis doctoral, Valencia, 2017). misma. Los ejemplos más inmediatos son los conventos de la Trinidad y San Vicente, que estaban situados extramuros, pero muy cercanos al núcleo urbano. Las manifestaciones de piedad que realmente nos interesan en este punto son aquellas que, debido a su duración y distanciamiento del municipio, se convirtieron en verdaderas romerías. Se produjeron dos salidas de este tipo: entre el 17 y el 25 de enero de 1456 y entre el 29 de agosto y 4 de septiembre del mismo año. En ambos casos se realizó una procesión desde la catedral hacia la puerta de san Vicente y allí se despidió a los peregrinos. A su regreso, se convocó otra procesión de recibimiento hasta los muros de la ciudad y de ahí de vuelta a la catedral ${ }^{37}$. En la documentación no consta el destino de la primera romería, solo hemos podido localizar, en el pago al presbítero encargado de organizar la salida, la referencia a que la romería iría "deffora de la ciutat per los lochs acostumats"38. Esta referencia a los "lugares acostumbrados" nos hace pensar en romerías anteriores, como la que tuvo lugar en 1452 y cuyo destino fue el monasterio de Santa María de el Puig, a unos $15 \mathrm{~km}$ de Valencia ${ }^{39}$. Este monasterio estaba cargado de simbología para los valencianos, ya que remitía directamente a la conquista cristiana. Cerca de ese lugar se libró, en 1237, la batalla definitiva que llevaría a la entrada de Jaume I en la ciudad unos meses después, y allí, por el mismo monarca, fue ordenado levantar un cenobio dedicado a santa María al encontrarse en la pequeña montaña aledaña una imagen de la Virgen enterrada y escondida en el interior de una campana ${ }^{40}$.

\footnotetext{
${ }^{37}$ Ejemplos más tempranos de estas romerías los encontramos en 1448, cuando se convocó una salida a la cartuja de Portaceli "per sanitat e pluia", o en 1449, cuando el destino fue la iglesia de santa María del Grau de la Mar. Guiral, “L'evolution du paysage...", 1606.

${ }^{38}$ AHMV, Manuals de Consells, A60, f. 60r. 16 de enero de1456. ("Fuera de la ciudad por los lugares acostumbrados").

39 AHMV, Claveria Comuna (albarans), O27, ff. 146v-147r. Valencia, 6 de mayo de 1452.
}

${ }^{40}$ Javier Domínguez Rodrigo, El Puig de Santa María: aproximación histórica y valoración crítica (Valencia: Publi- 
Este monasterio continuó siendo visitado en romerías en ocasiones posteriores, como por ejemplo en 1469, 1473, 1507 o $1532^{41}$.

En la segunda salida sí que aparece el lugar al que se dirigió esta pequeña peregrinación, el monasterio jerónimo de Santa María de la Murta de Alzira, situado a unos $50 \mathrm{~km}$ de la capital ${ }^{42}$. Este cenobio, fundado en 1376 bajo la protección del monasterio de Cotalba, adquirió fama desde el siglo $\mathrm{XV}$, siendo visitado en 1410 por san Vicente Ferrer y en diversas ocasiones por los jurados de la ciudad. Además, muchas de las familias del patriciado local, como los Vich y los Vilaragut, realizaron importantes donaciones durante el siglo $\mathrm{XV}$, ya que albergaba la venerada imagen de santa María de la Murta, encontrada, al igual que la del Puig, tras la conquista cristiana, en este caso entre unos matorrales de "murta" (mirto en valenciano ${ }^{43}$. Tampoco hay que olvidar que algunos monarcas, como Felipe II, lo visitaron, por lo cual fue un importante centro de peregrinación durante el medioevo y los primeros años de la Edad Moderna.

Como hemos comprobado, ambos monasterios custodiaban imágenes marianas de gran devoción en el Reino de Valencia, cuyo origen coincide en su aparición milagrosa con la conquista cristiana ${ }^{44}$. El hecho de que

trade, 1992).

${ }^{41}$ Estas romerías pueden documentarse gracias a la siguiente documentación inédita: AHMV, Manuals de Consells, A38, y Claveria Comuna, O29 y O50.

${ }^{42}$ AHMV, Manuals de Consells, A36, f. 129r-129v. Valencia, 29 de agosto de 1456.

${ }^{43}$ Luis Arciniega García, “Santa María de la Murta (Alcira): Artífices, comitentes y la Damnatio Memoriae de D. Diego Vich", en La orden de San Jerónimo y sus monasterios, coord. por Francisco Javier Campos (San Lorenzo de El Escorial: Ediciones Escurialenses, 1999), vol. 1, 269-292.

${ }^{44}$ El culto mariano en Valencia adquirió gran importancia desde la conquista, al imitar la ciudad la devoción de Jaume I. Se aúnan en él, por tanto, religiosidad e identidad. Serra Desfilis, "Memoria de reyes...", 156; María Elvira Mocholí Martínez, "La Virgen de la Seo y otros iconos reales en la ciudad de Valencia", Codex Aquilarensis, $\mathrm{n}^{\circ} 34$ (2018), 169-182. las procesiones para visitar estas imágenes traspasaran no solo los muros de la ciudad, sino también su jurisdicción nos habla de la importancia de esta gran secada, y de cómo las rogativas se fueron intensificando a medida que la sequía se recrudecía y se extendía en el tiempo.

\section{"PER ÇO NOTIFIQUEM". MANDA- TOS A LA POBLACIÓN}

Nos queda intentar averiguar cómo eran estas procesiones y con ello qué efecto podían tener en el paisaje visual y también sonoro de la ciudad. Por un lado, sabemos que el cabildo catedralicio y el poder municipal participaban en la procesión. Pero ¿qué papel desempeñaba la población de la ciudad en estas manifestaciones? Nuevamente la relación de la crida que nos ocupa será nuestra principal fuente de información. En el espacio dedicado a los mandatos a la población podemos leer: "Per ço notifiquen a tot feel chrestià e chrestiana que lo dit día de demà per lo matí sien a la dita Seu per acompanyar la dita processó e seguir aquella ab lums en les mans e en altra manera com pus devotament poràn, en manera que obtingam davant la maiestat divina la previsió e demana, e les dites oracions sien aceptables a aquella. Manat a cascú de aquells que habiten en los dits carrers per on la dita processó pasarà deveren lurs enfronts com mils puxen, e guanyaran los perdons acostumats"45.

Es decir, se convoca a toda la población cristiana (interesante la ausencia de referencia a las minorías religiosas que todavía habitaban en la ciudad, sobre todo a la musulmana) a que acudan con cirios en las $\operatorname{manos}^{46}$.

${ }^{45}$ AHMV, Manuals de Consells, A36, f. 53r. ("Por esto notificamos a todo fiel cristiano y cristiana que el dicho día de mañana por la mañana estén en la dicha Seo para acompañar la dicha procesión y seguir aquella con luces en las manos y en otra manera como más devotamente podrán, de modo que obtengan ante la Majestad Divina lo que se solicita, y que dichas oraciones sean aceptadas por Aquella. Se ordena a cada uno de los que habitan en dichas calles por donde pasa dicha procesión que limpien sus fachadas como mejor puedan y ganarán los perdones de costumbre".

${ }^{46}$ Aunque pueda parecernos lógica la no convocato- 
Además, se habla de oraciones, pero sin especificar cuáles. Aquí debemos acudir a las descripciones de los rezos que se producían en estas manifestaciones de piedad. Las oraciones de letanías se basaban en peticiones y solían tener una estructura fija, basada en un esquema pregunta-respuesta en el que el oficiante realizaba la oración y la congregación solía responder con un kyrie eleyson o un ora pro nobis ${ }^{47}$. En la época medieval, teniendo en cuenta la participación de los canónigos de la catedral, la música vocal acompañaría estas oraciones en la mayoría de las ocasiones. Se trataría de melodías sencillas y monódicas, extraídas del canto llano, de las que hemos encontrado un ejemplo en una fuente un poco posterior, el Cançoner de Gandia, de principios del siglo XVI. Se trata de una página dedicada a las letanías de San Pedro. En ella podemos diferenciar las partes realizadas por el oficiante y aquellas en las que intervendría la congregación ${ }^{48}$. Vemos, por tanto, cómo el paisaje sonoro de estas celebraciones estaría acompañado del tono solemne del canto llano, realizado en un juego

ria de musulmanes y judíos a este tipo de celebraciones, su asistencia era obligatoria en otro tipo de eventos comunitarios, como las entradas reales. Así lo muestran las ordenaciones por la entrada de Juan, príncipe de Girona y su esposa Matha d'Armagnac en Valencia en 1373, que fueron tomadas como modelo en entradas posteriores y en las que se pedía que estos dos colectivos recibieran a los príncipes con sus mejores galas: "Aiximateix sien aemprats los juheus e los moros de la ciutat que isquen reebre cascuns per si la dita Senyora, ab lurs mellors apparellaments, segons han acostumat e mils fer puxen". Salvador Carreres Zacarés, Ensayo de una bibliografía de libros de fiestas celebradas en Valencia y su Antiguo Reino (Valencia: Imprenta hijo de F. Vives Mora, 1925), vol. II, 27-33.

47 Richard Hoppin, La música medieval (Madrid: Akal, 2000), 135; Alison Latham, Diccionario enciclopédico de la música (México DF: Fondo de Cultura Económica, 2009), 867; Felipe Pedrell, Diccionario técnico de la música (Valladolid: Editorial Maxtor, 2009), 256, (1ª edición 1894); David Andrés, "Fit processio et cantantur antiphonae sequentes. Tipología de las formas de música litúrgica en los libros procesionales", Medievalia, ํㅡ 17 (2014), 103-129, especialmente 111.

${ }^{48}$ Biblioteca Nacional de Catalunya (BNC), Cançoner de Gandia, Ms. 1967, ff. 161v-162r. de preguntas y respuestas que acompañaría todo el recorrido ${ }^{49}$. En cuanto a la participación de instrumentos musicales en este tipo de procesiones, no hemos encontrado ninguna referencia en la documentación consultada, por lo que pensamos que tan sólo la voz, ya fuese cantada o declamada, sería el acompañamiento sonoro de estas manifestaciones religiosas.

Siguiendo con el texto de la mencionada crida, llama la atención al final de dicho mensaje el mandato a los vecinos de las calles por las que pasaría la procesión para que limpiaran las fachadas de sus casas. La palabra en valenciano antiguo enfront se refería tanto al muro como a la parte de la vía pública recayente frente a la casa, por tanto, deducimos que cada vecino debería limpiar la parte de la calle que ocupase su viviend $a^{50}$. Para otro tipo de celebraciones en las que las calles se convertían en escenario, como las entradas reales o la procesión del Corpus Christi, las crides solían exhortar a los vecinos a decorar las fachadas con tapices y a disponer enramaes de hierbas aromáticas en la calzada. Aparecen incluso prohibiciones para que los animales circulen por las calles del itinerario desde el día anterior a la fiesta, para que no ensucien el recorrido ${ }^{51}$. En el caso que nos ocupa, entendemos que, al tratarse de procesiones en que se buscaba mostrar el arrepentimiento y la contrición, se huía del carácter festivo y representativo de las celebraciones mencionadas anteriormente, por lo que las procesiones por el fin de la sequía no añadirían estos mandatos a los habitantes de las casas por las que discurría el itinerario.

Todas estas ordenanzas, acudir a la procesión con velas, rezar piadosamente e incluso limpiar las calles, tendrían una recompen-

\footnotetext{
${ }^{49}$ Otras formas musicales como las antífonas, las preces o los himnos también eran cantadas en las procesiones. David Andrés, "Fit processio...", 106-117.

${ }^{50}$ Antoni Maria Alcover y Francesc de Borja Moll, Diccionari català-valencià-balear, 10 de abril de 2019, enlace web.

${ }^{51}$ AHMV, Manuals de Consells, A29, ff. 9r-v. Crida de la procesión del Corpus, 2 de junio de 1428.
} 


\begin{tabular}{|c|c|c|c|c|}
\hline AÑO & FECHA & LUGAR DE DESTINO & CAPILLA/IMAGEN & ESTACIONES \\
\hline \multirow{2}{*}{1455} & 9 noviembre & Convento de San Agustín & Virgen de Gracia & \\
\hline & 12 diciembre & Convento de San Agustín & Virgen de Gracia & \\
\hline \multirow{22}{*}{1456} & 3 enero & Convento del Carmen & & Iglesia de santa Cruz \\
\hline & 14 enero & Convento de Predicadores & $\begin{array}{l}\text { Virgen de la } \\
\text { Misericordia }\end{array}$ & Iglesia de san Esteban \\
\hline & 17 enero & $\begin{array}{c}\text { Puerta de san Vicente para } \\
\text { acompañar la salida de la } \\
\text { romería a el Puig }\end{array}$ & & \\
\hline & 25 enero & $\begin{array}{l}\text { Puerta de san Vicente para } \\
\text { recibir a la romería }\end{array}$ & & \\
\hline & 28 enero & Convento de la Trinidad & & \\
\hline & 7 febrero & Convento de san Vicente & & \\
\hline & 10 febrero & Convento de san Francisco & & \\
\hline & 15 marzo & Convento del Carmen & & Iglesia de santa Cruz \\
\hline & 3 abril & $\begin{array}{l}\text { Convento de san Agustín. } \\
\text { Gracias por lluvia }\end{array}$ & Virgen de Gracia & \\
\hline & 20 julio & Convento de san Agustín & Virgen de Gracia & \\
\hline & 25 julio & Convento del Carmen & & $\begin{array}{c}\text { Iglesias de santa Cruz } \\
\text { y san Bartolomé }\end{array}$ \\
\hline & 30 julio & Convento de Predicadores & $\begin{array}{l}\text { Virgen de la } \\
\text { Misericordia }\end{array}$ & Iglesia de san Esteban \\
\hline & 7 agosto & Convento de san Francisco & & \\
\hline & 17 agosto & Convento de la Trinidad & & \\
\hline & 21 agosto & Convento de san Vicente & & \\
\hline & 25 agosto & Iglesia de san Esteban & & \\
\hline & 29 agosto & $\begin{array}{l}\text { Puerta de s. Vicente para } \\
\text { acompañar la salida de la } \\
\text { romería a la Murta }\end{array}$ & Virgen de la Murta & \\
\hline & 5 septiembre & $\begin{array}{l}\text { Puerta de san Vicente para } \\
\text { recibir a la romería }\end{array}$ & & \\
\hline & 14 octubre & Convento san Agustín & Virgen de Gracia & \\
\hline & 13 noviembre & Convento del Carmen & & $\begin{array}{c}\text { Iglesias de santa Cruz } \\
\text { y san Bartolomé }\end{array}$ \\
\hline & 29 noviembre & $\begin{array}{l}\text { Convento de san Agustín. } \\
\text { Gracias por lluvia }\end{array}$ & Virgen de Gracia & \\
\hline & 3 diciembre & Convento de Predicadores & $\begin{array}{l}\text { Virgen de la } \\
\text { Misericordia }\end{array}$ & Iglesia de san Esteban \\
\hline \multirow[t]{5}{*}{1457} & 6 febrero & Convento del Carmen & & $\begin{array}{c}\text { Iglesias de santa Cruz } \\
\text { y san Bartolomé }\end{array}$ \\
\hline & 20 febrero & Convento de Predicadores & $\begin{array}{l}\text { Virgen de la } \\
\text { Misericordia }\end{array}$ & Iglesia de san Esteban \\
\hline & 5 marzo & $\begin{array}{c}\text { Convento de san Agustín. } \\
\text { Gracias por lluvia }\end{array}$ & Virgen de Gracia & \\
\hline & 24 marzo & Convento del Carmen & & $\begin{array}{c}\text { Iglesias de santa Cruz } \\
\text { y san Bartolomé }\end{array}$ \\
\hline & 7 mayo & $\begin{array}{l}\text { Convento de san Agustín. } \\
\text { Gracias por lluvia }\end{array}$ & Virgen de Gracia & \\
\hline
\end{tabular}

- Tabla 1. Listado de procesiones, estaciones y destinos. Según la información extraída de las crides transcritas en los Manuals de Consells (AHMV, A36). 
sa, los "perdones acostumbrados". Esta es la información que nos dan las crides. No aparece referencia, como en otras procesiones por causas como victorias militares, bodas y nacimientos de la familia real, o incluso por exequias, a ordenaciones específicas hacia las órdenes religiosas o los gremios de artesanos. En este caso el llamamiento es general, a todo cristiano o cristiana, sin importar su pertenencia a cualquier organización religiosa o social. Este es un punto importante, ya que vemos, por tanto, cómo este tipo de procesiones pretendían movilizar a la mayor parte de población posible y conseguir así dar una imagen de unidad de toda la ciudad cristiana ante la adversidad ${ }^{52}$. Incluso para el propio Consell y el Cabildo catedralicio el hecho de convocar estas procesiones suponía una demostración de su preocupación por la situación, y su interés por mostrarse unidos ante las calamidades. En estas manifestaciones religiosas, además, la importancia del orden y la colocación de cada uno de los colectivos participantes era un reflejo del ideal de sociedad tripartita medieval que definiera, en el caso valenciano, el citado Francesc Eiximenis ${ }^{53}$.

En conclusión, nos encontramos ante una demostración de devoción piadosa que se traduce en uno de los momentos de comunión urbana más importantes de la época medieval, ya que, a diferencia de otras celebraciones como las justas, juegos de cañas o entradas reales, toda la población cristiana estaba invitada a participar, demostrando así una unidad ante la adversidad, siendo esta, en el caso que nos ocupa, la ausencia de lluvia.

Este artículo se ha planteado como introducción a un tema de investigación que consideramos mucho más extenso. El estudio y análisis pormenorizado de todas las crides, con sus mandatos e itinerarios, nos

\footnotetext{
${ }^{52}$ Kathleen Ashley y Wim Hüsken, Moving Subjects: Processional Performance in the Middle Ages and the Renaissance (Amsterdam-Atlanta: Rodopi, 2001).

${ }^{53}$ Francesc Eiximenis, Regiment de la cosa pública, ed. por Josep Palomero (Alzira: Bromera, 2009).
}

debe conducir en un futuro a la ya comentada realización de una cartografía virtual de los recorridos devocionales en la Valencia medieval, donde se puedan resaltar las similitudes y divergencias entre estas manifestaciones representativas de la piedad popular con otros acontecimientos, como las mencionadas celebraciones del Corpus Christi y las entradas reales producidas en la ciudad, actos a los que la historiografía local, quizá por su esplendor y porque han generado más documentación, ha prestado tradicionalmente más atención. La introducción del análisis de la piedad popular (en ocasiones dirigida por los poderes fácticos) en el campo de estudio de las celebraciones urbanas permite, de este modo, el acercamiento al fenómeno de la utilización de la trama urbana como escenario festivo y representativo de una manera más completa e integradora, creando un marco metodológico mucho más rico que si nos remitimos sólo a procesiones civiles o a grandes eventos vinculados con la corona. Valga pues esta aproximación como una primera puesta en valor del interés sociológico de este tipo de eventos en territorio valenciano.

\section{BIBLIOGRAFÍA}

Alberola Romá, Armando. "Procesiones, rogativas, conjuros y exorcismos: el campo valenciano ante la plaga de langosta de 1756". Revista de Historia Moderna. Anales de la Universidad de Alicante, 끄 21 (2003), 37-38.

Aldana Fernández, Salvador, coord. Monumentos desaparecidos de la Comunidad Valenciana. Valencia: Consell Valencià de Cultura, 1999.

Andrés Fernández, David. "Fit processio et cantantur antiphonae sequentes. Tipología de las formas de música litúrgica en los libros procesionales". Medievalia, $\mathrm{n}^{\mathrm{o}} 17$ (2014), 103-129.

Arciniega García, Luis. “Santa María de la Murta (Alcira): Artífices, comitentes y la Damnatio Memoriae de D. Diego Vich". En 
La orden de San Jerónimo y sus monasterios, coordinado por Francisco Javier Campos, vol. I, 269-292. San Lorenzo de El Escorial: Ediciones Escurialenses, 1999.

Ashley Kathleen y Wim Hüsken. Moving Subjects: Processional Performance in the Middle Ages and the Renaissance. Amsterdam-Atlanta: Rodopi, 2001.

Benito Goerlich, Daniel. El icono de Nuestra Señora de Gracia de Valencia: historia de la imagen y su templo de San Agustín y Santa Catalina 700 años después de su fundación. Valencia: Ajuntament de València, 2007.

Benito Goerlich, Daniel. El Real Monasterio de la Trinidad. Historia y Arte. Valencia: Consell Valencià de Cultura, 2008.

Benito Goerlich, Daniel. El Real Monasterio de San Agustín de Valencia: parroquia de Santa Catalina Mártir y San Agustín Obispo. Valencia: Institució Alfons el Magnànim, 2015.

Callado Estela, Emilio, Daniel Benito, Nuria Blaya, María Cruz Cabeza, Amparo Felipo y Alfonso Esponera. El Palau de la Saviesa. El Reial Convent de Predicadors de València i la Biblioteca Universitària. Catálogo de exposición. Valencia: Universitat de València, 2005.

Carreres Zacarés, Salvador. Ensayo de una bibliografía de libros de fiestas celebradas en Valencia y su Antiguo Reino. Valencia: Imprenta hijo de F. Vives Mora, 1925, vol.II.

Cruselles, José María. "Els conversos de València, el cens inquisitorial de 1506 i la família del mercader Lluís Vives". Futu$r a, \mathrm{n}^{-} 31$ (2015), 16-17.

Diccionari català-valencià-balear. http://dcvb. iecat.net/

Eiximenis, Francesc. Regiment de la cosa pública. Editado por Josep Palomero. Alzira: Bromera, 2009.

Falomir Faus, Miguel. Arte en Valencia, 14721522. Valencia: Consell Valencià de Cultura, 1996.
Galtier Martí, Fernando. “Los orígenes de la paraliturgia procesional de semana santa en Occidente". Aragón en la Edad Media, no 20 (2008), 349-360.

García Hinarejos, Dolores. Historia y arquitectura del convento del Carmen de Valencia. Valencia: Consorcio de Museos de la Comunidad Valenciana, 2009.

Guiral, Jacqueline. «L'evolution du paysage urbain à Valencia du XIII au XVI siècle». En la España medieval, no 7 (1985), 15811610.

Hauf i Valls, Albert. "Profetisme, cultura literària, i espiritualitat en la València del segle XV: d'Eiximenis i Sant Vicent Ferrer a Savonarola, passant pel Tirant lo Blanc". En Xàtiva, els Borja: una projecció europea. Catálogo de exposición, 115-116. Xàtiva: Ajuntament de Xàtiva, 1995.

Hinojosa Montalvo, José. "En torno a los judíos valencianos. La recuperación de una memoria olvidada". Hispania: Revista Española de Historia, vol. 50, nº 175 (1990), 921-940.

Hinojosa Montalvo, José. "Sederos conversos en la Valencia bajomedieval". Anales de la Universidad de Alicante. Historia Medieval, no 18 (2012-2014), 187-224.

Hoppin, Richard. La música medieval. Madrid: Akal, 2000.

Juliana Colomer, Desirée. "Fiesta y urbanismo. Valencia en los siglos XVI y XVII". Tesis doctoral. Universitat de València, 2017.

Latham, Alison. Diccionario enciclopédico de la música. México DF: Fondo de Cultura Económica, 2009.

Martínez de Toledo, Alfonso. Arcipreste de Talavera o Corbacho. Editado por Joaquín González Muela. Madrid: Castalia Clásicos, 1970.

Miralles, Melcior. Crònica i dietari del Capellá d'Alfons el Magnànim. Editado por Mateu Rodrigo Lizondo. València: Universitat de València, 2011. 
Mocholí Martínez, María Elvira. “La Virgen de la Seo y otros iconos reales en la ciudad de Valencia". Codex Aquilarensis, no 34 (2018), 169-182.

Narbona Vizcaíno, Rafael. “Las fiestas reales en la ciudad de Valencia entre la Edad Media y la Edad Moderna (siglos XIVXVII)". Pedralbes. Revista d'història moderna, no 3 (1993), 463-472.

Narbona Vizcaíno, Rafael. Valencia, municipio medieval: poder político y luchas ciudadanas (1239-1418). Valencia: Ayuntamiento de Valencia, 1995.

Narbona Vizcaíno, Rafael. "La justicia municipal en el Reino de Valencia (ss. XIII-XV)". Anales de la Universidad de Alicante. Historia Medieval, no 18 (2012-2014), 347-357.

Narbona Vizcaíno, Rafael. La ciudad y la fiesta: cultura de la representación en la sociedad medieval (siglos XIII-XV). Madrid: Síntesis, 2017.

Nirenberg, David. Communities of Violence. Persecution of Minorities in the Middle Ages. Princeton: Princeton University Press, 1996.

Pedrell, Felipe. Diccionario técnico de la música. Valladolid: Editorial Maxtor, 2009 (1 $1^{\underline{a}}$ edición 1894).

Peña Díaz, Manuel. “Leer, oír y hablar: sonidos cotidianos en la Barcelona del Quinientos". En Els sons de Barcelona a l'edat moderna, coordinado por Tess Knighton, 113-129. Barcelona: Museu d'Història de Barcelona-Ajuntament de Barcelona-Institució Milà i Fontanals/CSIC, 2016.

Ruiz Jiménez, Juan e Ignacio José Lizarán Rus. "Historical Soundscapes (c. 1200-c.
1800): An On-Line Digital Platform". En Hearing the city in Early Modern Europe, coordinado por Tess Knighton y Ascensión Mazuela-Anguita, 342-352. Turnhout: Brepols Publishers, 2018.

Ruzafa García, Manuel. "Las actividades industriales de la morería de Valencia". En Actas del VI Simposio Internacional de Mudejarismo, 269-286. Teruel: Centro de Estudios Mudéjares-Instituto de Estudios Turolenses, 1993.

Serra Desfilis, Amadeo. "Gli ordini mendicanti e la città: localizzazioni conventuali e urbanizzazione a Valencia (secoli XIII$\mathrm{XV})^{\prime \prime}$. En Storie di città e architetture. Scritti in onore di Enrico Guidoi, a cura di Guglielmo Villa, 95-112. Roma: Kappa, 2014.

Serra Desfilis, Amadeo. "Memoria de reyes y memorias de la ciudad: Valencia entre la conquista cristiana y el reinado de Fernando el Católico (1238-1476)". Codex Aquilarensis, nº 34 (2018), 143-167.

Soriano Sánchez, Rafaela y Francisco José Soriano Gonzalvo. San Vicente Mártir y los lugares vicentinos en Valencia. Valencia: Ajuntament de València, 2001.

Vauchez, André. "Liturgie et culture folklorique: les rogations dans La Legénde Dorée de Jacques Voragine". En Fiestas y liturgia, Actas del congreso celebrado en la Casa de Velázquez, 21-34. Madrid: Casa de Velázquez-Universidad Complutense, 1988.

Vauchez, André, ed. La religion civique à l'époque médiévale et moderne (Chretienté et Islam. Rome: École Française de Rome, 1995. 